\title{
LA REVOLUCIÓN CUBANA EN UN NUEVO CONTEXTO HISTÓRICO
}

\author{
Olga Fernández Ríos \\ Instituto de Filosofia de Cuba
}

\section{LA REVOLUCIÓN CUBANA EN UN NUEVO CONTEXTO HISTÓRICO}

Resumen: Se analizan importantes factores y contradicciones que influyen en el avance de la Revolución Cubana a partir de los acuerdos adoptados por el VI Congreso del Partido Comunista (PCC), celebrado en 2011. El Congreso ratificó la estrategia de desarrollo socialista y la implementación de un nuevo modelo de desarrollo económico y social que rompe con estructuras y prácticas estadocentristas que predominaron en el llamado "socialismo real", y a la vez que ratificó la propiedad estatal sobre los más importantes medios de producción, amplío las formas no estatales de propiedad y gestión económica. Todo ello introduce cambios en la estructura socioclasista y en el modo de construir el socialismo, lo que genera nuevos desafíos para garantizar la continuidad de la transición socialista. Se trata de un nuevo contexto histórico en el que institucionalidad y participación popular deben fortalecerse para garantizar la permanente renovación de la hegemonía socialista.

Palabras clave: Transición socialista, Sexto Congreso del PCC, modelos de desarrollo, neodesarrollismo, desafíos sociopolíticos

\section{THE CUBAN REVOLUTION IN A NEW HISTORICAL CONTEXT}

Abstract: The author analyzes important factors and contradictions that affects the advancement of the Cuban Revolution since the deals adopted by the Sixth Congress of the Cuban Communist Party (PCC), held in April 2011. The Congress ratified the socialist strategy for implementing a new model of economic and social development that rejects the centrist structures and practices of the "real socialism". The new model reaffirms the state property of the main means of production, but also extend the role of non state forms of social property and economic management. The current context and policies are producing changes in the socio-classist structure and in the conceptions and ways to built socialism, in fact generating new challenges in the road to guarantee the socialist transition. Concludes that it is a new historical context in which these transformations include perfecting political institutions and revitalizing popular participation in order to guarantee the permanent renovation of socialist hegemony.

Key words: Socialist transition, Sixth Congress of the Cuban Communist Party, development models, neodevelopment, sociopolitical challenges 


\section{INTRODUCCIÓN}

El presente trabajo analiza varios factores que influyen en el avance al socialismo en Cuba en un nuevo contexto en el que se transforma el modelo de desarrollo económico y social del país, a través de un necesario y complejo proceso cuyas bases fueron trazadas por el VI Congreso del Partido Comunista de Cuba (PCC) celebrado en abril de 2011. No es posible analizar ese proceso sin tener en cuenta que, si bien su génesis tiene que ver con el agotamiento del anterior modelo, los cambios se producen en una sociedad que es diferente a la que existía décadas atrás; lógicamente no es la misma que en los 60, 70, los 80 o los 90 . Factores socioeconómicos, culturales y demográficos han cambiado como producto del impacto de los importantes logros de la revolución y de disfunciones que han existido. También el contexto internacional ha cambiado sensiblemente, sobre todo desde el derrumbe del socialismo en la URSS y Europa del Este.

Lo cierto es que es una sociedad marcada por elementos contradictorios: por una parte hay muchas fortalezas acumuladas y compromisos a favor de la opción socialista, pero también hay diferentes expectativas acerca de las fórmulas económicas emergentes, y no faltan voces que comienzan a coquetear con preceptos favorables a un reacomodo en el presionante mundo del capitalismo. Más recientemente, el restablecimiento de relaciones diplomáticas con Estados Unidos, se suma como un factor que puede encandilar a algunos con falsas ilusiones de cambios en el imperialismo norteamericano, y con la idea de que las trabas para el avance económico desaparecerán a partir de algunas de las medidas adoptadas por Estados Unidos favorables a los viajes a Cuba y a ciertos intercambios con la isla, a pesar de que el bloqueo económico y comercial sigue en pie. Afortunadamente la dirección del país, fiel a su legado, ha dejado clara la posición independentista y de mantenimiento de la soberanía nacional, lo que corresponde a los intereses del pueblo cubano que mayoritariamente respalda la opción socialista. No obstante, es innegable que se enfrentan nuevos y complejos desafíos.

El análisis requiere precisar sobre importantes factores que interactúan en el escenario sociopolítico, y que influyen en la continuidad de la transición socialista. A la vez hay que tener en cuenta algunos elementos conceptuales para precisar el contexto en que hoy se desenvuelve la Revolución Cubana: primero, sobre la transición socialista; el tema de los modelos para su desarrollo y la confrontación socialismo-neodesarrollismo y segundo, sobre las coordenadas del nuevo modelo que se implementa. Entre los temas y problemáticas susceptibles de ser analizados, escogimos los que constituyen desafíos a enfrentar en tres de las más importantes dimensiones del actual proceso: los cambios en la estructura de la propiedad social y la necesaria renovación de la hegemonía socialista; los impactos sociopolíticos de los cambios en la institucionalidad política y la democracia, y en la profundización de la interacción Estado-sociedad civil; y la situación que se genera en el campo de la justicia social y su jerarquización.

\section{LA TRANSICIÓN SOCIALISTA, EL TEMA DE LOS MODELOS DE DESARROLLO $Y$ LA CONTROVERSIA SOCIALISMO- NEODESARROLLISMO}

En Cuba se experimenta un proceso de transición socialista, concepto que identifica el sentido anticapitalista y de acumulación de valores socialistas ${ }^{1}$ que va predominando en una sociedad que rompe con los patrones asociados al capitalismo. Es un proceso en el que se modifican al unísono las estructuras socioeconómicas y políticas, los individuos y sus subjetividades, la cultura y la vida ético-espiritual.

En gran medida la transición se desarrolla en condiciones inéditas, a partir de los marcos históricos de cada país que definirán continuidades, rupturas y ajustes coyunturales, sobre todo hoy, dada la compleja situación internacional signada por la globalización neoliberal, el dominio de los bloques de poder imperialistas y del sistema de instituciones financieras internacionales que los sostienen, junto con los negativos impactos mediáticos que modelan argumentos para justificar injerencias y guerras contra naciones, pueblos y culturas, considerados de la periferia.

El caso de Cuba con la injerencia y el bloqueo de EEUU es un ejemplo donde la continuidad está dada por mantenerse una estrategia de orden socialista, mientras que las rupturas se derivan de las combinaciones de éxitos, insuficiencias y errores cometidos. También por cambios de coyunturas históricas que han influido sensiblemente en los problemas económicos que el país ha enfrentado. En ese contexto no han estado ausentes la crítica y autocrítica por parte de los gobernantes y la consulta popular como instrumento de cambio.

La experiencia del socialismo a lo largo del siglo $X X$ muestra que es un negativo reduccionismo concebir la transición a través de un esquema único, y hoy se hace evidente la posibilidad de encausarla a través de diferentes modelos de desarrollo. Lo estamos viendo en Cuba, conscientes de que el tema es muy polémico si se analizan las experiencias del frustrado socialismo real y del llamado socialismo de mercado en China y Vietnam. También porque se relaciona con los contenidos de la transición en países subdesarrollados, de ahí lo que algunos estudiosos han considerado como una transición 
socialista larga o extraordinaria para generar las condiciones económicas y políticas pro socialistas (FIGUEROA, 2009). En eso también influye la interrelación de dos ámbitos que condicionan la transición socialista en los países subdesarrollados: los adversos factores externos que genera la geopolítica imperial y lo relacionado con la base territorial en que se desenvuelven los procesos revolucionarios en términos de independencia $y$ soberanía nacional que son condiciones ineludibles en una sociedad que construye el socialismo. ${ }^{2}$

Para llevar a cabo una revolución socialista con menos desarrollo, el avance de la economía es imprescindible, pero partiendo de una concepción sistémica de la sociedad, ya que si bien no hay socialismo sin desarrollo de las fuerzas productivas y sin condiciones para cubrir las necesidades de las personas, tampoco hay socialismo solo con desarrollo económico. ${ }^{3}$ Este es uno de los temas presentes en estudios marxistas en América Latina que valoran las complejidades que deben enfrentar los países con insuficiente desarrollo económico que necesitan bases para sostener las políticas de igualdad y justicia social (KATZ, 2011).

El tema es de la mayor vigencia y requiere de análisis, cuando en América Latina emergen proyectos nacionales de corte antiimperialista, también anticapitalista, con diferentes matices los que, de una u otra forma, albergan debates y acciones políticas en los que se enfrentan tendencias neo desarrollistas y pro socialistas.

Ese debate está directamente relacionado con el comienzo de la transición socialista, pero también con su continuidad, como es el caso de Cuba, lo que nos obliga a meditar sobre la confrontación que hoy se da entre socialismo y neodesarrollismo cuando algunos, incluso desde la izquierda, consideran que el segundo es la respuesta adecuada para eliminar las contradicciones derivadas del subdesarrollo o de las políticas neoliberales, posición que elude, cualquier intento a favor de una sociedad post capitalista (KATZ, 2010). Para Cuba el tema es de vital importancia pues a pesar de los más de cincuenta años de Revolución Socialista con grandes logros, no faltan criterios trasnochados que apelan a la misma salida para resolver los problemas económicos que se enfrentan.

Debe tenerse en cuenta que el esquema prodesarrollista tiene perspectivas contrarias a la transición socialista, entre otras razones, como analiza el argentino Claudio Katz (2006), porque abre muchos espacios para hablar del capitalismo y deja poco lugar para sugerir algo concreto sobre el socialismo. Otra cosa es la construcción del socialismo que requiere que en cada momento se concreten medidas que minimicen el individualismo y vayan borrando la enajenación humana.

\subsection{La implementación de un nuevo modelo de desarrollo}

Es justo reconocer que el modelo socioeconómico que hoy se desmonta generó un avance económico y cultural sin precedentes en la sociedad cubana, con fórmulas de desarrollo sociopolítico para garantizar empleo, salud, erradicación del hambre y la pobreza, educación y previsión social con oportunidad de acceso universal y con un alto grado de cohesión y de solidaridad interna y hacia el mundo. En todo momento ha existido una voluntad política para preservar esos y otros valores cimentados durante más de cincuenta años y a la vez conservar la soberanía nacional, el control de los recursos naturales y garantizar que los principales medios de producción sigan siendo propiedad de la nación y no patrimonio privado.

Pero desde mediados de los años 80 las fallas del modelo se hicieron evidentes: mecanismos económicos excesivamente centralizados, junto con distorsiones en la planificación de los sectores fundamentales de la economía, en la correlación planificación-mercado y en los vínculos entre lo nacional y lo local, entre otros factores, a los que se sumaron la compleja situación económica que se generó a partir del derrumbe del socialismo en la URSS y Europa del Este y el recrudecimiento del bloqueo norteamericano a través de dos leyes aprobadas por el Congreso de Estados Unidos: la Ley Torricelli en 1992 y la Ley Helms Burton en 1996. Todo ello provocó una aguda crisis económica con incremento del mercado negro o economía sumergida, con brotes de corrupción.

En aquellas condiciones se adoptaron varias medidas, entre las que destacamos tres de las más importantes: implementar el llamado trabajo por cuenta propia; desarrollar el turismo extranjero como fuente recaudadora de divisas que, como sabemos, trae consigo efectos indeseables, y el establecimiento de una dualidad monetaria con las contradicciones que este tipo de medida introduce. Todo ello generó diferencias sociales e inequidad en los ingresos de la población, junto con la imposibilidad de que todos los ciudadanos tuvieran acceso a los mercados de divisas y del turismo. Desde el presente debemos reconocer que no había otras salidas, y que se logró lo fundamental: la sobrevivencia de la Revolución Cubana, garantizada en gran medida por la heroicidad del pueblo y por la profunda labor educativa de la dirección del país, encabezada por Fidel Castro.

El complejo proceso iniciado en los 90, si bien logró preservar la Revolución Cubana y sus logros fundamentales, complejizó la estructura socio clasista abriendo una tendencia hacia su heterogeneidad, lo que en mi criterio es irreversible, pero puede y debe ser controlado a través de políticas socioeconómicas, educativas y de justicia social. 
La situación señalada no debe obviarse para analizar y entender el proceso de cambios que hoy se lleva cabo en Cuba como la apertura de un nuevo modo de construir el socialismo, que ya era evidente en algunos elementos de la reforma a la Constitución en 1992 que refrendó importantes cambios en materia de propiedad social e institucionalidad los que, lamentablemente, no fueron debidamente implementados hasta casi 20 años después. Fue en la primera década del siglo XX cuando se agudizaron consecuencias negativas de aquella demora y de algunas de las medidas emergentes que se habían adoptado, revelándose con fuerza las razones para implementar cambios en la estructura de propiedad y en otras esferas.

Entre 2005 y 2007 tres acontecimientos impactaron fuertemente el imaginario popular $y$ la conciencia colectiva sobre la necesidad de los cambios: la intervención del Líder de la Revolución Cubana en la Universidad de La Habana, en noviembre de 2005, que alertó sobre vulnerabilidades que podían afectar el avance del proyecto socialista, entre ellas las de carácter subjetivo; su ulterior enfermedad en 2006 que levantó el tema del liderazgo y de las garantías de continuidad de la Revolución Cubana y la intervención de Raúl Castro el 26 de julio de 2007 que promovió un debate nacional, y un diagnóstico popular crítico acerca de caminos que resultaron errados, de las insuficiencias y deformaciones económicas e institucionales que venían afectando el desarrollo del país.

Después de un amplísimo debate popular, el VI Congreso del PCC en 2011 ratificó la ruptura con el modelo de desarrollo predominante durante más de 50 años, y replanteó el tema de la propiedad social, lo que se vincula directamente con la institucionalidad política y con las expectativas y contradicciones en el mundo de las subjetividades. Pero también introdujo nuevas señales sobre la correlación entre factores internos e internacionales, cuando a pesar de la permanencia del bloqueo de EEUU, se abordaron las urgencias que el país debe enfrentar con el concepto de que el desarrollo del socialismo, depende en gran medida de factores endógenos, de lo que seamos capaces de lograr. También sobre la visión de logros y beneficios, no solo para el futuro, sino también para el presente. Esto significa que el tránsito socialista debe acumular logros que beneficien a las actuales generaciones, y que a la vez sean condiciones y estímulos para la continuidad. Se trata de que los pasos y métodos utilizados no erosionen la meta estratégica del socialismo y el comunismo, la superación de la enajenación humana, pero que a la vez estimulen a las generaciones involucradas, sin obviar la significación de la vida cotidiana de las personas.

El hecho es que después de 56 años, la Revolución Cubana enfrenta uno de los retos más importantes de su historia: garantizar su continuidad en condiciones muy adversas, dadas por limitaciones económicas y de recursos y por los negativos impactos de la crisis por la que atraviesa el capitalismo, con sus secuelas de afectaciones a los países subdesarrollados. Se trata de una nueva etapa de la transición socialista encaminada a lograr lo que oficialmente se ha definido como un socialismo próspero y sostenible.

Los principales cambios económicos se orientan en el documento que opera con sentido programático bajo el nombre de Lineamientos para el desarrollo de la política económica y social del PCC y la Revolución, en el que sobresalen cinco acuerdos de carácter estratégico: 1) la reafirmación de los objetivos de carácter socialista, 2) la ratificación de la empresa estatal socialista como principal actor económico, al concentrar la propiedad de los medios fundamentales de producción. Incluye la separación entre funciones estatales y empresariales; 3) la ampliación de formas de propiedad que rompan con la excesiva centralización, el paternalismo estatal y el burocratismo que caracterizaron a las experiencias socialistas en el siglo XX; 4) favorecer la interrelación entre centralización estatal y descentralización que promueva desarrollo local y 5) lograr equilibrio entre planificación y mercado (PARTIDO COMUNISTA DE CUBA, 2011b).

De hecho se está dando un replanteo de la función del Estado con relación a la vida socioeconómica, conjuntamente con la apertura a formas de propiedad asociadas al desarrollo de cooperativas urbanas -que se suman a las cooperativas agrícolas que ya existían en el país- y al llamado trabajo por cuenta propia, sobre todo en el sector de la gastronomía y los servicios que, si bien estaban legalizados desde hace varios años, es a partir de 2011 que se fortalecen como importantes espacios y actores económicos.

Todo lo anterior introduce cambios en el modo de construir el socialismo, en las formas de relación entre individuo-Estado y entre Estadosociedad civil. Significa pasar de un Estado que dominaba completamente el entramado económico y que protegía con subsidios universales a toda la población, independientemente de sus ingresos os aportes al desarrollo del país, a un Estado que debe equilibrar las diversas formas de propiedad y que debe continuar protegiendo los intereses de una sociedad que se hace más diversa.

Eso significa que se complejizan las relaciones económicas y políticas, si se tiene en cuenta que los cambios impactan la vida sociopolítica cuando el Estado deja de ser el único actor económico, cuando surgen nuevos actores económicos que introducen diferencias sociales y hacen la sociedad más heterogénea, cuando se requiere buscar nuevas fórmulas de protección estatal que se alejen del paternalismo y los subsidios estatales para todos, pero que mantengan la médula de las políticas de justicia social que constituyen 
uno de los pilares y compromisos ineludibles de la Revolución Cubana.

El contexto que genera el nuevo modelo de desarrollo económico y social requiere como nunca antes, tener en cuenta que la construcción del socialismo es un proceso integral que debe sumar condiciones y hegemonía socialistas que se expresen en un sistema de emancipación integral y múltiple del ser humano y la sociedad, lo que no se logra solo con desarrollo económico. De ahí que el proceso de rectificación que introduce el VI Congreso sea más profundo que los anteriores realizados en el país que no alteraron en lo fundamental la concepción de un Estado que liberaba a las personas de muchas responsabilidades, mientras que en la actualidad el cambio en la relación entre individuo y Estado requiere también de un acomodo de las subjetividades a la nueva situación. A la vez, la rectificación en marcha multiplica los sectores socioeconómicos, y por tanto complejiza la estructura y los posicionamientos socio clasistas, reordena la fuerza laboral, reconoce con mejor tino la autonomía y responsabilidad empresarial, la necesaria descentralización de facultades hacia los municipios y el papel de la correlación planificaciónmercado.

En esta nueva etapa conceptos y complejidades sobre el socialismo, la propiedad, el trabajo, la democracia, la política, la individualidad, la ética, los espacios públicos, los problemas demográficos y migratorios, entre otros asuntos, son analizados con mayor amplitud y perspectivas, lo que requiere una visión sistémica de la sociedad para evaluar los impactos sociopolíticos que se desprenden de las transformaciones.

Con las medidas adoptadas se pretende fortalecer una economía que sustente el socialismo, pero a la vez se deben perfeccionar los mecanismos políticos y de distribución de riqueza; no puede haber espacio para terapias de choque, ni decisiones que pongan en peligro el control socialista de la economía y la soberanía nacional sobre los recursos ${ }^{4}$. Los problemas que deben ser eliminados devienen desafíos, que al igual que las causas que los generan, tienen un doble carácter: estructural-funcional y de corte axiológico e ideológico por adentrarse en factores subjetivos, en las conductas y educación de las personas, - sobre todo las nuevas generaciones de cubanos y cubanas -, en valores y proyectos de vida individuales y sociales, en sentimientos y actitudes y por supuesto en la ideología dominante. Todo ello trae necesarias implicaciones que sin dudas complejizan el panorama sociopolítico en el país, pero que contribuyen a una concepción más abierta y revolucionaria sobre los objetivos socialistas.

En mi criterio lo más importante y sensible del actual proceso, es cumplimentar sobre nuevas bases lo que ha sido ratificado por la dirección del país con el mayoritario respaldo popular: mantener la estrategia de desarrollo socialista. Para hacerlo, conjuntamente con los cambios en la economía, debe fortalecerse la institucionalidad y perfeccionarse los métodos de dirección sobre la base del permanente involucramiento popular en la toma de decisiones y en el control de la gestión y los recursos como principal antídoto contra el burocratismo y las manifestaciones de corrupción. También fomentar educación y cultura ética y política que fortalezca los valores socialistas basados en la jerarquización del trabajo como principal medio de vida y de realización humana, a la par que se mantenga una alta sensibilidad para auscultar los efectos que las medidas adoptadas tengan sobre la población y sobre las políticas de justicia social.

\section{TRABAJO POR CUENTA PROPIA, COOPERATIVAS, PLANIFICACIÓN, MERCADO}

Las transformaciones en la propiedad comenzaron con una extensión y fortalecimiento del llamado trabajo por cuenta propia, sector que no se inscribe dentro de las formas de propiedad social, pero que no la contradice. Trabajo por cuenta propia es un término que identifica relaciones económicas diferentes al incluir empleadores y empleados que no trabajan en dependencias del Estado. Parte de ese sector puede devenir en la formación de empresas mercantiles y de servicios a pequeña escala, pero también pudiera favorecer la creación de nuevas cooperativas urbanas, sector más afín a los objetivos socialistas. Todo ello debe impactar favorablemente la generación de empleos y la ampliación de servicios a la población, descargando al Estado de gestiones que le ocupaban de forma sobredimensionada y sin posibilidades de resolver necesidades en una amplísima gama de productos y servicios.

El llamado cuentapropismo y el sector cooperativo se despliegan en los marcos locales y forman parte de una estrategia de desarrollo territorial con regulaciones a través de la política tributaria sobre ingresos y sobre fuerza de trabajo. Algunos de los pasos dados en esos sectores son significativos y ameritan valorar sus límites y equilibrios, sobre todo el cuentapropismo, en lo referido al carácter del trabajo de los contratados o asalariados de este sector, y a la apropiación privada de los excedentes. Las medidas que se aplican no descartan, más bien debieran estimular, la formación de cooperativas en esferas donde ahora se expande el cuentapropismo.

Otro gran esfuerzo se despliega para combinar la planificación central y los elementos de mercado que se introducen, conscientes de que se trata de uno de los temas más complejos, polémicos y sensibles de la transición socialista, que para algunos se relaciona directamente con las causas 
del fracaso del socialismo en la Unión Soviética y en los países de Europa del Este que aplicaron el modelo soviético hasta su desintegración, o que ya lo habían reformado como es el caso de Yugoslavia y Hungría.

Sin desconocer el importantísimo papel de la planificación en la transición socialista, la experiencia histórica ha demostrado que los extremos que contraponen planificación y mercado, no garantizan la continuidad de ese proceso. De ahí que identificar socialismo con planificación, o pensar que solo la planificación garantiza socialismo, es errado, pues ésta no es más que una forma de gestión y organización económica que debe insertarse en el complejo de factores económicos, políticos y sociales a favor del socialismo. ${ }^{5}$ Tampoco es una certeza, que la introducción regulada de mecanismos de mercado sea incompatible con los objetivos de la transición socialista, proceso que necesita flexibilidad y uso controlado de diferentes herramientas económicas. ${ }^{6}$

En el caso de Cuba se enfrentan desafíos en este terreno para lograr una gestión combinada del plan con el mercado, lo que incluye inversiones y transacciones económicas reguladas por la planificación, y definiciones del radio de acción del mercado y su alcance, de ahí que se reconozca la empresa estatal socialista como forma predominante en el modelo económico que se construye (PARTIDO COMUNISTA DE CUBA, 2011b). Esto no excluye que se analicen otras experiencias de países que desarrollan un llamado socialismo de mercado, como es el caso de China y Vietnam.

Raúl Castro, al presentar el informe central al VI Congreso del PCC, precisó que el incremento del sector no estatal de la economía, lejos de significar una supuesta privatización de la propiedad social, está llamado a convertirse en un factor facilitador para la construcción del socialismo, ya que permitirá al Estado concentrarse en la elevación de la eficiencia de los medios fundamentales de producción, y desprenderse de la administración de actividades no estratégicas para el país (PARTIDO COMUNISTA DE CUBA, 2011a).

En nuestro criterio lo que decidirá el rumbo futuro es que la diversidad de formas de propiedad y gestión se equilibren a partir de una permanente y sistémica renovación de la hegemonía socialista, frente a cualquier intento que favorezca acciones meramente desarrollistas o abiertamente capitalistas.

\section{DESAFÍOS SOCIOPOLÍTICOS}

En Cuba hay muchos análisis acerca de las transformaciones asociadas al nuevo modelo de desarrollo económico y social, cuyo éxito depende en gran medida de la capacidad que se genere para favorecer el predominio de relaciones socioeconómicas y políticas que reproduzcan socialismo. Dicho con otras palabras, mantener la hegemonía socialista en una sociedad que es más diversa, en cuanto a sectores y actores socioeconómicos, y que amplía sus relaciones con el mundo. En ese contexto una gran responsabilidad corresponde a la labor política e ideológica que debe perfeccionarse, si se tiene en cuenta la variedad de interpretaciones que pueden generar los cambios en marcha, incluyendo confusiones e impaciencias en parte de la población.

Dos factores de gran peso político en las nuevas condiciones que rodean la continuidad de la Revolución Cubana, deben tenerse en cuenta. Primero, en algún momento no se contará con la presencia del liderazgo histórico de la Revolución Cubana. Segundo, el restablecimiento de relaciones diplomáticas con Estados Unidos. Este último factor generará una alta tensión política que estamos llamados a enfrentar como nación: las nuevas características y patrones que adopte la injerencia del imperialismo norteamericano. Lo que no cabe duda es que la injerencia se mantendrá, aunque detrás de una fachada de tolerancia hacia el proceso cubano, con dos evidentes motivaciones, las expectativas de cambios en Cuba vistos como oportunidad para socavar la orientación socialista, y la necesidad de frenar el creciente rechazo a EEUU en varios países de América Latina, y el brote de procesos nacionales antiimperialistas.

Esa injerencia ya está perfilada, como queda claro en la intervención del Presidente Barak Obama el 17 de diciembre de 2014. En esa ocasión, a la vez que anunciaba el restablecimiento de relaciones diplomáticas con Cuba, en dos ocasiones expresó la intención de continuar apoyando a la sociedad civil cubana para que se una a Estados Unidos y de esa forma, los "[...] ciudadanos (cubanos) y no sólo los líderes, formen nuestro futuro." (OBAMA, 2014). Por supuesto, esas intenciones no son nuevas, pero hoy las tratarán de cumplimentar en condiciones más amistosas, lo que puede confundir a algunos en la isla.

En nuestro criterio, para enfrentar el nuevo contexto es ineludible el desarrollo económico, pero tomará tiempo ${ }^{7}$, por lo que en el corto plazo las acciones en el campo de las relaciones políticas e ideológicas y del vínculo con las masas también pasan a un primer plano, y deben hacer muy visible la reafirmación del poder conquistado por el pueblo cubano desde 1959. A ello se une un importante presupuesto: el poder político de naturaleza popular es una conquista de la Revolución Cubana a partir de la noción fidelista y guevariana que considera que en Cuba el sujeto político es el pueblo, depositario del poder político y no un participante más del mismo ${ }^{8}$. Hegemonizar ese poder, está en la génesis de la Revolución que empoderó a amplios sectores a partir del concepto pueblo, formulado por Fidel Castro en 1953 que lo vincula con lucha, que en las 
condiciones actuales la asociamos a acciones para mantener la hegemonía socialista9 .

Se trata entonces de gobernar los cambios, evaluar y medir sus impactos, valorar en cada momento la correlación entre consenso político, gobernabilidad y legitimidad de los que desempeñan funciones de dirección. Incluye la reestructuración del consenso político logrado bajo el anterior modelo. En ello gran incidencia tienen tres condicionantes de carácter sociopolítico que a la vez generan complejos desafíos para la continuidad de la Revolución Cubana: 1) promover un reforzamiento de la democracia socialista, que de hecho es muy diferente a como se plantea en el subversivo Programa Democracia diseñado por la Agencia para el Desarrollo de Estados Unidos (USAID) y la National Endowment for Democracy (NED). No se trata de asimilar los mecanismos demoliberales, sino de lograr un mayor empoderamiento de los sectores populares que se exprese en la ampliación de la participación popular en todas sus formas y en el perfeccionamiento de la representación ciudadana en órganos de poder, conjuntamente con el perfeccionamiento institucional ya iniciado. Todo ello debe reforzar las vínculos entre Estado y sociedad civil; 2) la ratificación de políticas de justicia social en el contexto de una mayor diversidad y complejidad socio clasista que amerita un análisis masivo de las fórmulas para garantizar igualdad social y protección estatal; 3) la permanente reconstrucción del consenso político en las condiciones que genera el nuevo modelo de desarrollo socialista.

Esos temas se tornan en problemáticas y contenidos de primer orden de la transición socialista en Cuba y deben analizarse de manera integral y no por separado. Requieren de un enfoque sistémico, dialéctico y cultural de la sociedad que permita abordar las transformaciones económicas y sociopolíticas en su interrelación orgánica y considerar los entrecruzamientos entre política y economía; política, cultura y sociedad; individuo y política, ética, moral, valores y política; Partido, Estado y Sociedad Civil; ciudadanía y política.

En Cuba hay condiciones para lograr un mayor empoderamiento de los sectores populares, al existir un importante acumulado institucional y educacional que ha reivindicado durante años un nuevo tipo de interrelación y acercamiento entre los que suelen llamarse dirigidos y dirigentes, a favor de los primeros, y reconociendo que mucho depende de la cultura política y de la construcción de incentivos que refuercen constantemente las confianzas en el Estado y en el Partido Comunista.

Por otra parte, nadie cuestiona que sigan existiendo gobernantes y gobernados, conscientes de que uno de los grandes cambios que la Revolución produjo ha sido crear las condiciones para que el ejercicio de la política no sea patrimonio de los políticos profesionales, sino del pueblo como sujeto político plural. A la vez, está demostrado que el sistema político con que contamos es perfectible, de ahí que es posible reforzar las dos dimensiones más visibles del empoderamiento popular: la representación en los órganos estatales y la participación política masiva. Ambos requieren de educación, cultura e ideología política, ambiente participativo y fomento de motivaciones personales y sociales, traspaso de información, distinción entre poder y administración.

\section{CORRELACIÓN ESTADO-SOCIEDAD CIVIL}

Este es un tema estratégico que está en el centro de los análisis y debates que tienen lugar en la Cuba actual y que de una u otra forma ratifican la importancia de lograr la mayor interrelación entre poder político y construcción de democracia como contenido del Estado lo que requiere de un mayor acercamiento entre Estado y sociedad civil que rompa barreras entre ambos.

En la transición socialista el Estado es necesario, siempre y cuando genere canales participativos y vasos comunicantes con la sociedad civil, que inclinen la balanza cada vez más al desarrollo de las potencialidades políticas de la sociedad civil en el sentido que Marx (1974, p. 24) expresa en Crítica del Programa de Gotha, cuando plantea que la verdadera libertad consiste en "[...] convertir al Estado de órgano que está por encima de la sociedad en órgano completamente subordinado a ella." La fortaleza de ese Estado en la transición socialista se pone a prueba en dos niveles: a) su voluntad para representar los intereses de quienes ostentan el poder político que en el caso de Cuba es el pueblo; y b) su capacidad para interactuar con el conjunto de la sociedad, con todos los actores sociales, para representar a la realidad socioclasista, a la sociedad en su conjunto, para ir desdibujando la separación entre individuo y Estado, entre Estado y sociedad civil.

Este es uno de los temas más complejos en la historia del socialismo al vincularse con la relación entre lo individual y lo social, aquí expresado en términos de la interrelación entre el ser humano marcado por sus intereses individuales y el ser humano con potencialidades políticas como ciudadano del Estado. Se trata de eliminar la enajenación que existe en el capitalismo cuando el ciudadano común es separado de la política concebida como ocupación de políticos profesionales y de élites preconcebidas para la toma de decisiones en nombre de la sociedad. Es eliminar la concepción liberal del Estado como intermediario entre los ciudadanos y las decisiones y dar un vuelco a la concepción que separa el interés público del privado. Son temáticas que debe retomar cualquier proyecto emancipatorio pro socialista, y Cuba no es la excepción. 
En Cuba se está dando un redimensionamiento del Estado en pos de una interacción más lógica y equilibrada entre lo que pudiera llamarse Estado garante que todo lo garantiza y el que es capaz de generar gobierno con diversas formas económicas que independicen a las personas de la tutela económica del Estado, pero que a la vez éste favorezca las políticas de justicia social inherentes a un proceso socialista. En ese contexto es que el Estado se debe modernizar en términos de estructura, funciones y correlaciones con la propiedad y la gestión. A la vez la sociedad civil se hace más heterogénea y se perfila como espacio de desarrollo de nuevas formas de propiedad con impactos en las subjetividades y en las relaciones de producción. Esto también introduce cambios en la interrelación de ambas esferas y, como ya hemos planteado, en las relaciones individuo-estado e individuo- sociedad, con diferencias a etapas anteriores.

El empoderamiento popular que reivindicamos no debe ser abstracto o declarativo. Se debe materializar en un crecimiento cuantitativo y cualitativo de la participación popular en todas sus formas. Se asienta en una comprensión de que en la transición socialista la política tiene tareas nobles: lograr una interacción entre los diferentes sectores de la sociedad cuando acoge los deseos y los malestares, las ansiedades y las dudas de la gente, a la vez que incorpora sus vivencias al discurso público. Dar cabida a la subjetividad de los gobernados y oportunidades a los ciudadanos, de reconocer sus experiencias cotidianas como parte de la vida en sociedad (LECHNER, 2006).

En esa dirección el VI Congreso del Partido Comunista de abril de 2011, llamó a un fortalecimiento de la institucionalidad, a una mayor precisión sobre los roles que corresponden al Partido, al Estado y a los sectores organizados de la sociedad. De igual forma se pronunció la Conferencia Nacional del PCC celebrada en enero de 2012 que reconoció la necesidad de dar un vuelco a los métodos de trabajo político e ideológico con el objetivo de acercar cada vez más las bases sociales a las esferas encargadas de la toma de decisiones y viceversa.

\section{LA JUSTICIA SOCIAL Y SU NECESARIA JERARQUIZACIÓN}

La Revolución Cubana acumula importantes logros en materia de justicia social y es un país en el que existe una cultura de los derechos. Hasta hoy se ha mantenido el principio de avanzar en el crecimiento y desarrollo económico, sin afectar las políticas socialesenbeneficio de todalasociedad. Sinembargo, el modelo estado-centrista introdujo gratuidades de varios servicios, medidas asistencialistas $y$ subsidiarias para todos, independientemente del aporte de los ciudadanos al avance del país, lo que no contribuyó al desarrollo económico por sus negativas influencias en la productividad y en las subjetividades, particularmente en las motivaciones laborales. A ello se unieron inapropiados conceptos de homogeneidad social, a partir del subsidio estatal a la distribución generalizada de bienes de consumo, y un sobredimensionamiento del empleo no productivo en dependencias del Estado.

Todo ello introdujo reflejos ideológicos y éticos, con derivaciones sobre el tejido social, la productividad y la civilidad que desvirtúan la concepción socialista, de ahí que hoy se transforme esta esfera, lo que acarrea enormes retos: por una parte se deben eliminar las distorsiones, y por otra parte deben mantenerse altos niveles de justicia, igualdad y equidad social, sin ellos no hay socialismo. Ala vez tienen mucho peso los mencionados cambios en el sistema de la propiedad que han generado nuevos sectores económicos y diversos niveles de ingresos que propician una diversidad social que no existió durante más de 50 años.

En ese contexto, el VI Congreso del PCC aprobó decisiones en la dirección de erradicar las disfunciones y rescatar el principio de distribución socialista según el trabajo, sin perder de vista las necesidades de determinados sectores de la sociedad.

Una premisa para analizar este tema es que, desde los años 90 se fue conformando la comprensión de que en las condiciones económicas en que tiene lugar la transición socialista en este país, no es posible lograr, ni a corto, ni a mediano plazo, la estratégica homogeneidad social, cuando hay factores que posibilitan y perfilan la existencia de diferencias sociales, sobre todo en los ingresos. Pero también hay conciencia de que deben favorecerse condiciones que eviten que esas diferencias se profundicen y que se tornen en profundas desigualdades sociales de diverso corte, lo que las haría irreversibles. O sea hay que lograr una tendencia favorable al avance hacia la mayor igualdad y equidad social posible.

EI VI Congreso reconoció la importancia de enfrentar los problemas sociales, y no fue ajeno a la necesidad de atender los factores que conspiran contra la plena realización de la individualidad, lejos del slogan capitalista referido a la igualdad de oportunidades que supuestamente éste propicia, y que en realidad es una falacia levantada sobre la base de un individualismo exacerbado y de la privatización de esferas que deben ser responsabilidad del Estado.

En los Lineamientos aprobados por el VI Congreso del PCC acertadamente se reconocieron los problemas que afectan a personas vulnerables como son los impedidos para el trabajo, debido a problemas físicos o mentales y con dificultades familiares para apoyarlos; los que por diversas razones enfrentan riesgos en materia de alimentación, 
y los adultos mayores, sobre todo en un contexto de envejecimiento poblacional, que por una parte es un logro de las políticas de la Revolución y que, por otra parte genera contradicciones que deben ser atendidas.

Sin embargo, a pesar de esas importantes precisiones, es un tema que aún está insuficientemente tratado, que requiere de mayor análisis y atención, y de profundización de políticas y medidas que encaucen los cambios sin prescindir del lugar de la igualdad social en la anatomía de la transición socialista ${ }^{10}$. Eso se relaciona directamente con la preservación de los niveles de igualdad social que la Revolución Cubana ha defendido, no solo con relación a los ingresos, sino también en materia racial, de género, de preferencias sexuales, de suscribir o no determinada religión, entre otras.

Si bien el cambio del modo de construir el socialismo requiere minimizar las políticas paternalistas y ajustar las medidas para el otorgamiento de subsidios estatales diferenciados según las necesidades de personas y familias, en lugar de subvenciones al consumo de todos los ciudadanos, el Estado debe seguir garantizando el grueso de las políticas sociales vinculadas con salud, educación, seguridad y prevención social, garantías de empleo, alimentación, atención a los problemas de vivienda, y la protección a la niñez y a los sectores vulnerables, entre otros.

Esa responsabilidad y compromiso no debe tener ninguna alteración, pero lo que si debe reforzarse son dos planos en los que la intervención del Partido Comunista y del Estado es crucial para continuar la implementación de los cambios: primero, rechazar cualquier tendencia economicista o neodesarrollista que limite y coarte los objetivos socialistas; segundo, propiciar una estrategia sociopolítica favorable al enfoque integral y sistémico de los cambios que incluya la medición de sus impactos en la sociedad y la adopción de políticas encaminadas a frenar el brote de desigualdades o de inequidad social que se genere.

Resulta un imperativo ir ajustando los cambios, no solo por razones coyunturales, sino también por los objetivos estratégicos. Todo ello genera condiciones muy complejas, por los obstáculos materiales a enfrentar, y por la necesidad de modificar patrones éticos, ideológicos y de conductas que han introducido deformaciones de principios de igualdad, equidad y justicia social al confundirlos con medidas que eximan a las personas de sus responsabilidades individuales ante el trabajo, su familia y la sociedad, lo que además de recargar innecesariamente al Estado, propicia distorsiones socioeconómicas que obstaculizan el avance al socialismo.

Pero cuatro años después de iniciada la reforma al modelo de desarrollo socialista, serán cinco cuando se celebre el VII Congreso del PCC convocado para abril de 2016, el problema se torna más abarcador y complejo que lo que se recoge en las directrices aprobadas en 2011, pues la práctica social va mostrando las disfunciones que puede generar la coexistencia de diversos sectores económicos, y sus impactos sociales e ideológicos. Hoy es evidente que la continuidad de los cambios requiere una evaluación rigurosa de las diferencias sociales que afloran, de ahí que coincidimos con los autores que plantean que el tratamiento a la problemática de la igualdad y la equidad social, no debe limitarse a la eliminación del paternalismo estatal que favorece el llamado igualitarismo; a la preservación de las conquistas acumuladas y a la atención a personas con condiciones de vulnerabilidad. Se requiere mucho más: continuar monitoreando y midiendo las desigualdades que se puedan ir sumando, y actuar sobre ellas con políticas y programas sociales que refuercen instrumentos de equidad y que atajen la profundización de brechas de desigualdad social, lo que es incompatible con los objetivos socialistas (PIETRO, 2012, 2013).

Todo ello se asocia a la necesidad de continua profundización de las políticas de justicia social y a la reivindicación del trabajo como vía fundamental de realización personal y de desarrollo social, a lo que se une la recuperación del principio de distribución según el aporte del trabajo.

La correlación entre capacidades, trabajo y necesidades debe quedar más clara en la estrategia de orden socialista en Cuba, lo que debe influir en el creciente reconocimiento del importante rol de la individualidad en el socialismo, tema en el que debe profundizarse por su valor intrínseco y para desmitificar una de las más dañinas interpretaciones esquemáticas acerca del socialismo, la referida a que en esa sociedad se anula lo individual al subordinarse a lo social de forma absoluta. Urge revertir ese distorsionado concepto.

Tanto la justicia social como el lugar de la individualidad son temas reconocidos por la matriz marxista del socialismo. Siempre requerirán de permanente análisis y contrapunteo con todos los sectores del pueblo por su vínculo con las bases fundacionales y con el humanismo de la Revolución Cubana.

\section{CONCLUSIONES}

Las revoluciones no son estáticas, tienen que ratificarse y refundarse continuamente, y la cubana no es una excepción, y hoy necesita cambios en el modo de construir el socialismo, los que ya comenzaron a implementarse, con una combinación de cautelas y urgencias, pero también sobre la base de los enormes logros socioeconómicos, políticos y culturales que ya forman parte de la identidad nacional.

Es un país donde historia y cultura favorecen 
la permanente revitalización de la Revolución en la misma medida en que sale airosa de los retos que enfrenta, necesitados de respuestas y aportes que sumen y reproduzcan socialismo, teniendo en cuenta que en todas las esferas se deben fortalecer los factores que hacen la revolución viable, sostenible y con acumulados de prosperidad.

La sociedad cubana y su sistema político tienen condiciones para enfrentar exitosamente los riesgos internos y externos que pueden atentar contra la continuidad del camino escogido hace más de 55 años. Desde el ángulo de la economía ya se cuenta con una proyección que requiere de permanente monitoreo en dos direcciones que se complementan, para evitar el predominio de mecanismos favorecedores de la propiedad privada, y para garantizar la hegemonía socialista en todos los terrenos.

A la vez se requiere de una proyección política apegada a las concepciones matrices que desde 1959 definieron al pueblo como el sujeto de la revolución y garante del mismo, teniendo en cuenta que entre los valores entonces cimentados, está la ruptura con formas tradicionales de concebir la labor política convirtiéndola en una arte y una ciencia al servicio de los intereses populares, lo que hoy debe mantenerse en un marco social más diverso y heterogéneo

Son concepciones fidelistas que no pierden de vista la sólida filiación anti sistémica de Cuba al ser el primer país de América Latina y El Caribe en romper con los esquemas y poderes hegemónicos de Estados Unidos, y con las formas de dominación imperialista en los planos nacional e internacional. Y son las condiciones en las que se ha desenvuelto la sociedad cubana desde 1959 y que no han desaparecido cuando hoy el imperialismo norteamericano sigue siendo la peor amenaza a los pueblos que osen desafiarlo.

Todo ello amerita sumar esfuerzos para construir una teoría y una práctica política que desde los actuales presupuestos sean capaces de reivindicar el núcleo del proyecto revolucionario en las nuevas condiciones que marcan su continuidad: la renovación permanente del empoderamiento popular. En las condiciones actuales urge retomar de forma precisa y explícita lo concerniente al poder político, definido desde 1959 como poder del pueblo, con mayor visibilidad a partir de acciones concretas, teniendo en cuenta que el poder político no es algo estático o abstracto, sino que debe reafirmarse y reconstruirse permanentemente a través de diversas vías. Se trata de un objetivo inaplazable cuando el país se esfuerza por superar la práctica de diseñar la política a partir de imperativos coyunturales y se transita a un modelo que responda a necesidades macro económicas y sociopolíticas.

Si la vida del socialismo y su breve historia ha demostrado que el estado centrismo no es el camino; que las relaciones de propiedad deben inclinar cada vez más su balanza a favor de diferentes fórmulas de propiedad social, de igual forma se ha demostrado que el camino de las relaciones políticas debe ensancharse y cada vez más propiciar el empoderamiento popular e invertir la relación de dominación de los que dirigen hacia los dirigidos. Son objetivos de la política en las condiciones que introduce la transformación del modelo de desarrollo socioeconómico en Cuba. Tienen que ver con el Poder político y los sujetos del cambio, y se relacionan con el predominio de condiciones económicas, sociopolíticas, culturales e ideológicas favorables a la reproducción de relaciones y valores socialistas. En teoría podemos analizarlos como dos esferas con identidad propia, pero en la práctica son indivisibles.

Otro objetivo en las nuevas condiciones, es que el Estado y la sociedad civil se integren cada vez más en un sentido de complementariedad que conduzca a lo que Gramsci conceptualizó como Estado Integral y Ético, concepto que deberemos profundizar. Toda la racionalidad política, científica y revolucionaria indica que el rol de la sociedad civil cubana debe reforzarse como espacio de reproducción de socialismo, lo que significa que si en otras etapas la clave de la victoria estuvo en el logro de la unidad popular frente al imperialismo norteamericano, proceso complejo que contó con el enorme liderazgo de Fidel Castro, hoy es necesario seguir atendiendo simultáneamente los factores que propicien unidad y hegemonía socialista, desde perspectivas ideo políticas y éticas encaminadas a preservar y reproducir el poder popular conquistado desde 1959 y a prevenir y contrarrestar las tendencias a la fragmentación por la que apuesta el enemigo.

$\mathrm{Si}$ algún elemento conclusivo podemos añadir para cerrar esta intervención es la convicción de que en el nuevo contexto que combina la continuidad de las transformaciones del modelo de desarrollo económico y social con los inevitables cambios de liderazgo revolucionario y con las nuevas perspectivas de relaciones con Estados Unidos, la Revolución Cubana tiene un solo camino por el que apostamos: ratificarse y refundarse simultáneamente como proceso socialista y de liberación nacional. Ese es el camino escogido por el pueblo cubano y como sabemos, es muy raro que los pueblos se equivoquen.

\section{REFERENCIAS}

CASTRO, F. La historia me absolverá. La Havana: Palacio de Justicia, 1953. Autodefesa.

CHE GUEVARA, E. El Socialismo y el Hombre en Cuba. In: Che Guevara Presente: antología mínima. La Habana: Editorial de Ciencias Sociales, 2011. 
FIGUEROA, V. Economía Política de la transición al socialismo: experiencia cubana. La Habana: Editorial de Ciencias Sociales/Ruth Casa Editorial, 2009.

GONZÁLEZ, J. L. A. et al. Sobre la transición socialista en Cuba: un simposio. Temas, La Habana, n. 50-51, p. 126-162, abr./sept. 2007.

KATZ, C. Las disyuntivas de la izquierda en América Latina. La Habana: Editorial de Ciencias Sociales, 2010.

Modelos, ensayos y balances del socialismo. In: ZHUKOVSKII, I. E. L. Europa Oriental: del derrumbe al neoliberalismo. La Habana: Editorial Ciencias Sociales, 2011.

Socialismo o neodesarrollismo. La Haine, [S. I.], 2006. Disponible en:<http://www.lahaine.org/ b2-img/katz_soc.pdf>. Acceso en: 1 jan. 2016.

LECHNER, N. Las sombras del mañana. In: NECOCHEA, H. R. Obras Escogidas I. Santiago de Chile: LOM Ediciones, 2006.

MARX, C. Crítica al Programa de Gotha. In: ENGELS, F. Marx, Engels: obras escogidas. Moscú: Editorial Progreso, 1974. Tomo III.

OBAMA, B. Intervención del Presidente de Estados Unidos Barak Obama el 17 de noviembre de 2014. Periódico Granma, La Habana, nov. 2014. Não paginado.

PARTIDO COMUNISTA DE CUBA. Informe Central al VI Congreso del PCC. Periódico Granma, La Habana, abr. 2011a.

Lineamientos de la Política económica y social del Partido y la Revolución. 2011b. Disponible en:<http://www.granma.cubaweb.cu>. Acceso en: 1 jan. 2016.

Resolución sobre los Lineamientos de la Política Económica y Social del Partido y la Revolución. Periódico Granma, La Habana, abr. 2011c.

PIETRO, M. E. Desde el fondo del caldero: la reforma económica cubana y la equidad social I. Cuba Contemporánea, [s. I.], oct. 2013. Disponible en:<http://www.cubacontemporanea.com/specials/ desde-el-fondo-del-caldero-observando-la-reformaeconomica-cubana-desde-la-equidad-social>. Acceso en: 1 jan. 2016.

Retos y cambios en la política social. In: ALEJANDRO, P. V.; VILLANUEVA, O. E. P. Miradas a la economía cubana: el proceso de actualización. La Habana: Editorial Caminos, 2012.

\section{NOTAS}

1 Lo fundamental para el análisis, con alcance metodológico y político, es reconocer la necesidad de un período entrecapitalismo y comunismo, que Marx, para las condiciones de países desarrollados identificó como primera fase del comunismo, teniendo en cuenta que el desarrollo de las fuerzas productivas podía generar los acumulados económicos para una transformación de las relaciones de producción y una distribución acorde con el trabajo. No pueden obviarse los aportes de Lenin quien a partir de sus teorías del desarrollo desigual del capitalismo y del eslabón más débil, se refiere a un nuevo período, no previsto por Marx, para crear las condiciones del socialismo, concepto con el que identificó la primera fase de la sociedad comunista (GONZÁLEZ et al, 2007).

2 El concepto leninista de desarrollo desigual es una de las claves para analizar lo que hoy se conceptualiza como centro y periferia, norte y sur, y sirve de pauta para analizar la complejidad de la transición socialista en países como Cuba.

3 Pero si bien es acertado y tácticamente necesario, plantearse la posibilidad del triunfo revolucionario y su avance en países subdesarrollados, no puede subvalorarse la importancia que tiene el que se multipliquen los escenarios nacionales en que ese proceso se encause. La tesis de Che Guevara de crear, dos, tres, muchos Vietnam no ha perdido su vigencia como lo demuestran los cambios en la correlación de fuerzas que se vienen dando en América Latina desde los años 90 del pasado siglo y lo que ellos significan para el avance de la Revolución Cubana.

4 En la Resolución aprobada por el VI Congreso del PCC sobre los Lineamientos de la política económica y social del Partido y la Revolución se plantea que: "La política económica del Partido se corresponderá con el principio de que sólo el socialismo es capaz de vencer las dificultades y preservar las conquistas de la Revolución", y que "[...] en la actualización del modelo económico primará la planificación, la cual tendrá en cuenta las tendencias del mercado." (PARTIDO COMUNISTA DE CUBA, 2011c). Al respecto el informe al VI Congreso del PCC presentado por Raúl Castro se plantea que "[...] el incremento del sector no estatal de la economía, lejos de significar una supuesta privatización de la propiedad social, [...], está llamado a convertirse en un factor facilitador para la construcción del socialismo, ya que permitirá al estado concentrarse en la elevación de la eficiencia de los medios fundamentales de producción, propiedad de todo el pueblo, y desprenderse de la administración de actividades no estratégicas para el país." (PARTIDO COMUNISTA DE CUBA, 2011a).

5 Claudio Katz (2011, p. 224) se refiere a este tema al analizar críticamente los trabajos de P. Cockshott y A. Cottrell que identifican socialismo con planificación compulsiva y con uso social del excedente y eso no basta para que sea socialismo al ser reducido solo a distribución, puntualizando que no basta manejar de manera centralizada ese excedente para crear una sociedad que supere al capitalismo, resumiendo que "[...] socializar la miseria no es un proyecto liberador." 
6 Se debe trabajar en forma más cooperativa sin someterse a las fuerzas disolventes de mercado, ahí se distorsionó un aspecto clave de la transición que es la conveniencia de que el mercado subsista solo en el primer sector de la economía para que su eliminación en el segundo apuntale la socialización con un equilibrio entre producción y consumo durante la transición (KATZ, 2011).

7 En Cuba la transición socialista se ha desenvuelto en condiciones muy difíciles por ser un país subdesarrollado y neocolonial que ha tenido que enfrentar contextos geopolíticos muy adversos por la continua hostilidad de los gobiernos de EEUU, el recrudecimiento del bloqueo y las agresiones terroristas y mediáticas. Además por las influencias que tuvo del llamado socialismo real y por los dramáticos impactos derivados del derrumbe del socialismo en la URSS y Europa del Este.

8 Vale la pena destacar el análisis realizado por Ernesto Che Guevara (2011) en El Socialismo y el Hombre en Cuba donde profundizó sobre la dialéctica ser humano, masas populares y vanguardia política como premisas de una concepción de democracia alternativa a la burguesa. Es donde expone su concepción de Hombre Nuevo como ideal y un objetivo de ser humano permeado por valores éticos en cuya formación se involucran factores objetivos y subjetivos como son la actitud ante el trabajo y el papel de los estímulos, la educación y la cultura.

9 En su alegato- defensa en el juicio por el Asalto al Cuartel Moncada el 26 de julio de 1953, conocido como La Historia me Absolverá, Fidel Castro (1953) expone su concepto de pueblo vinculado a la lucha: e integrado por obreros, campesinos pobres, maestros, profesores, pequeños comerciantes, y otros sectores populares. El concepto se complementa al no aceptar como pueblo "[...] a los sectores acomodados y conservadores de la nación [...] " y precisa cuando reconoce como pueblo a la gran masa "[...] que ansía grandes y sabias transformaciones en todos los órdenes y que estará dispuesta a todo para lograrlo [...] ", especialmente, "[...] cuando haya adquirido plena conciencia clasista y, con ella, conciencia de su fuerza." (CASTRO, 1953, p. 33).

10 Algunos datos del debate popular que respaldó las decisiones que fueron adoptadas por el VI Congreso del PCC muestran el elevado número y la calidad de las propuestas sobre cuestiones de gran sensibilidad para las personas y para las familias a lo largo de todo el país. Resulta interesante constatar la receptividad que el Congreso tuvo con relación a las opiniones de la población, en particular sobre temas de gran sensibilidad para personas y familias como por ejemplo el referido a la necesidad de ir creando las condiciones para la paulatina desaparición de la libreta de abastecimientos que como se plantea en el Informe Central al VI Congreso "[...] fue sin dudas el asunto que provocó más intervenciones de los participantes en el debate y es lógico que así fuese." junto a otros lineamientos que se refieren a temas que afectan directamente a las personas como son la política de precios, la transportación de pasajeros, la educación, calidad de los servicios de salud pública y la unificación monetaria y que fueron los que motivaron mayor cantidad de propuestas (PARTIDO COMUNISTA DE CUBA, 2011a).

\section{Olga Fernández Ríos}

Licenciada en Historia

Doutora en Ciencias Filosoficas pela Academia de

Ciencias de Cuba, La Habana

Miembro de la Academia de Ciencias de Cuba y Investigadora Titular y Secretaria Científica del Instituto de Filosofia de Cuba

E-mail: olgafe@gmail.com

\section{Instituto de Filosofia de Cuba}

Calle Calzada 251, esquina a J. El Vedado, Plaza de la Revolución, La Habana/Cuba 